\title{
Undergraduate Students' Perspective On Self-Directed Learning In Speaking
} Skill

\author{
Rida Yulianti \\ $\underline{\text { rida.yulianti17017@student.unsika.ac.id }}$
}

Fauzi Miftakh

fauzi.miftakh@unsika.ac.id

Wahyudin Fitriyana

wahyudin.fitriyana@staff.unsika.ac.id

\section{Universitas Singaperbangsa Karawang}

\begin{abstract}
This study aims to describe undergraduate students' perspectives on the implementation of self-directed learning in improving speaking skills. The participants of this research are $8^{\text {th }}$ semester students at Universitas Singaperbangsa Karawang with the amount of 30 students. This study employed descriptive method, where the data gained through semistructured interview and questionnaires. The findings indicated that all participants agreed that self-directed learning is an effective method that is used outside the classroom. They also agreed that self-directed learning can help them achieve their learning goals and get used to being more active and responsible in their learning process. In addition, in carrying out self-directed learning activities, most of the participants prefer to use audio-visual media. Furthermore, this study suggests teachers to provide a foothold to students about the importance of self-management in the learning process towards self-directed learning so that students are more independent and can achieve the learning objectives.
\end{abstract}

Keywords: Students' Perspective; Self-directed Learning; Independent Learning

\section{INTRODUCTION}

Along with the very rapid development of science and also accompanied by technological advances, people are forced to be able to survive independently without much dependence on others (Douglas C. and Morris S. R. 2014). In addition, the case also has an impact on the way of learning English for EFL students. Currently, in obtaining a brief understanding of the subject matter, students cannot rely solely on the teacher's explanations in class, but they need to further enrich their understanding of learning independently outside the classroom. This means that students can gain a better understanding of the material. This students' initiative can improve their cognitive skills, especially in English subjects. The strategy for students to solve this problem is called SDL (Self-Directed 
Learning) where students are forced to study independently outside the classroom to gain more understanding and be actively involved in their own learning activities. Humaira \& Hurriyah (2017) defines SDL as a learning process in which students are responsible for their own learning activities. This is based on the purpose of learning using this method, namely to gain a deep understanding of their needs, express their goals, determine appropriate resources, decide on their own learning strategies, and estimate their learning outcomes. Students can carry out SDL simply to expand their knowledge more than they get from their teachers in class because if only class activities are relied on by students, it can limit their knowledge and can even make students left behind than other students who are more active in learning independently.

Currently, the object of research that is of interest to many researchers is the communicative ability of students in English. This is based on the main objective of learning English, namely students have the ability to communicate with others in English orally. Therefore, many researchers have conducted research by emphasizing research variables on English speaking ability to improve communication skills. This view is also supported by Kosar \& Bedir (2014) which states that students' speaking skills really need to be improved so that students are able to communicate directly in English. Teachers also need to optimize efforts in managing learning strategies in the classroom so that students can express their ideas and opinions by speaking English (Razmjoo \& Ardekani, 2011). Most of the students agree that the ability to survive in speaking English is an important outcome in learning English (Graham, 2007). Therefore, through mastering speaking skills, students can obtain information from others and engage in actual conversations (Rohmah, 2012).

However, a study conducted in Kenya by Sarwar et al (2014) found that even smart students in the class who scored well in written tests, they also still had difficulties in conveying something by speaking in English. This shows that speaking skills are quite difficult for students to master because ESL students in Kenya still find it difficult to express their own ideas by speaking fluently in English. Moreover, students in Indonesia are EFL learners, which means English is not a second language that they can find in their daily lives. In addition, Vu \& Shah (2016) believe that student learning success is influenced by their independence in learning outside the classroom. This is because students who do independent learning can understand their needs in learning languages and can also organize their own learning activities to achieve their learning goals. This statement is supported by Amdt (2017) who stated that autonomous learning allows students to control their own learning activities. This means that students are aware of holding their own responsibility in their own learning. Therefore, SDL is an additional strategy that can be applied by students where students can deepen their knowledge of the subject matter and they can also be more responsible for themselves as the main role in learning activities. 
However, Humaira \& Hurriyah (2017) stated that students in Indonesia rely too much on teacher explanations in class activities and they even tend to be passive during the learning process in class. This is a serious problem that needs to be explored and solved so that they do not have bad study habits. Nevertheless, the research conducted by them is still general in nature because students only enter SDL for general English subjects at school, it means that the main object of research is not particular English. Therefore, the researcher intends to explore further about the students' perspectives on SDL that they apply to their additional learning strategies in improving their speaking skills.

\section{LITERATURE REVIEW}

\section{Previous Related Study}

Hawkins (2018) conducted research on SDL related to learning strategies in English programs. Her study argued that the theori of self-directed learning from the field of adult education should be considered and carried out side by side with the other language learning strategies, autonomous learners, and independent learning in this type of tutor setting. On the other hand, Muradi (2018) also examines the importance of SDL in the language teaching and learning process. Another study conducted by Arndt (2017) found SDL handout information to provide students with some guidelines regarding the achievement of the English skills they need using independent learning strategies.

\section{Self-Directed Learning}

Humaira \& Hurriyah (2017) highlighted Self-Directed Learning (SDL) as an individual learning process that highlights the initiative of students in diagnosing their learning needs, formulating their learning goals, and evaluating their learning outcomes by themselves. As the well-known theory above believes that student initiative is born from SDL strategies. This means that students who have a good sense of responsibility in their learning aim to gain more understanding for their own needs in learning. Moreover, this view is supported by Williamson (2007) who defines SDL as a learning process in which students have the main responsibility and learn independently in their learning activities. Hendry \& Ginns (2009) also believe that SDL is a learning process in which students make decisions and organize their own learning activities according to their needs.

Garrison (1997) highlights a model that focuses on various dimensions of SDL such as self-monitoring involving cognitive abilities, self-management involving contextual control, and finally motivational factors requiring entry and task actions. A model is shown in the following figure: 


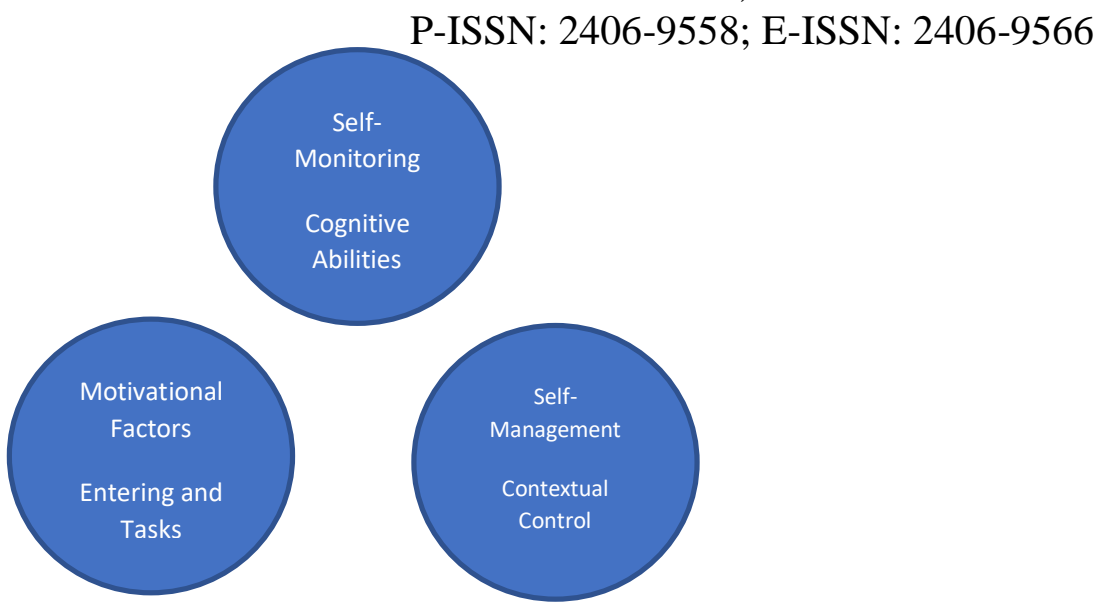

Figure 1 : Self-directed Learning Dimensions by Garrison (1997)

Through the dimensions above, students can be given special SDL strategies to be carried out outside the classroom so that SDL learning is effective for students. Positive decisions can be made by students so that they can be motivated and competent in their own learning process (Moradi, 2017). O'shea (2003) states that students who engage in SDL strategies need regulation, intrinsic and extrinsic motivation, and control during their learning activities. These factors indicate that in carrying out the SDL strategy for students, motivation must exist and grow.

\section{Speaking}

Speaking is one of kind of communication which involved two person or more that speak and listen to respond each other purposes or meanings. Johnson and Morrow (1981) defined speaking as a popular term of oral communication that people usually use, involved two or more people in which listener or speaker should react to what they listen to and make a contribution on the communication. This shows that to be able to connect with each other and to create warm relationships in society, people must be able to communicate effectively. This is what underlies the importance of learning to speak. In addition, speaking cannot be mastered easily by students because many students have difficulty in mastering speaking skills in English. Therefore, some aspects of speaking must be improved by students in order to be able to master good speaking skills. Brown (2001) has put four criteria needed by students, these aspects are pronunciation; native and notive ways of producing sound, fluency; ability to speak automatically and quickly, vocabulary; critical aspect to convey successful communication, and accuracy; the suitability between the language produce to the target language norms.

\section{METHOD}

\section{Design and Samples}

The researcher conducted qualitative research and adopted descriptive design since this research aims to describe undergraduate students' perspectives on SelfDirected Learning in speaking skill. Hence, descriptive design is also suitable for this research because it aims to explore in depth the events or experiences from an individual subject or groups. In addition, the study takes place in University of 
Singaperbangsa Karawang. It is the only one state university in Karawang. The participants of this research is $8^{\text {th }}$ semester students with the amount of 30 students. The students in this semester have been experienced well about the learning strategy that they used for improving their English proficiency or achieving some subjects in class. They have their own learning strategy with a various kind of it. Therefore, the data collected can be heterogeneous and the outcomes can be more natural.

\section{Instrument and Procedure}

The researcher used two instruments, they were semi-structured interview and questionnaire. The interview section is guided by the researcher, but if it is needed more information, the researcher is allowed to ask further questions. The researcher interviewed the participants through WhatsApp media. For the questionnaire, it is provided on a google form. The researcher made the questionnaire by using google form in order to give the flexibility to the participants in answering the questions. Those instruments are used to observed undergraduate students' obvious view in Self-Directed Learning method according to their experience.

\section{Data Analysis}

In analyzing the data, the researcher applied data analysis techniques based on Burns' theory (2010) which categorized some data analysis techniques as follow: First, collecting all data which have been obtained towards questionnaire and interview and put raised answers in order to answer research questions. Second, defining the data into more specific patterns or categories. Third, comparing the different data in order to find out whether the data is suitable each other. Fourth, building meanings and interpretations. Fifth, reporting the outcomes

\section{RESULT AND DISCUSSION}

\section{Undergraduate students' interest in self-directed learning}

The researcher found that self-directed learning method was owned and applied by all participants. They have good interest and almost all of them are interested in English. It is based on some of their favorite activities such as playing games, watching movies, listening to songs, and many more. Their enthusiasm for implementing self-directed learning allows them to enjoy their learning activities so that their learning goals and strategies can be managed well by them. Therefore, activities outside the classroom that they do is to improve their English skills. Moreover, when students are aware of their own learning needs and goals, they will be more motivated in learning English, especially speaking skill. Participant 3 (R3) added that self-directed learning made learning time more efficient, but the role and presence of the teacher is still needed to guide us in learning because the teacher can also provide a deeper understanding of the material we are studying. Furthermore, participant five (R5) mentioned that there are some successes from several independent learners who used SDL learning methods such as Rich Brian, 
a famous rapper from Indonesia who are able to achieve a successful career in the United States. The way he learns English is just by watching videos on YouTube. Therefore, the opportunity to achieve learning goals is owned by independent learners. According to F. Du as quoted by Hurriyah and Humaira (2017), independent learning activities carried out by students can facilitate students in achieving learning goals. In addition, one of the participants mentioned that there are many independent learners who can achieve success and learning goals themselves, such as Rich Brian, a famous rapper from Indonesia who has a successful career in the United States. The most interesting thing about him is, he makes watching on youtube as a medium for learning English and the results are amazing. That is, greater opportunities to achieve learning goals can be owned by independent learners.

\section{Speaking skill in self-directed learning}

In general, the participants agreed that the independent learning method was not effective enough to improve speaking skills. As respondent number three (R3) said that we should practice with friends or alone to improve our speaking skills. He also emphasized several views that our speaking skills can be supported by SDL and considered to four criteria of good speaking (pronunciation, vocabulary, fluency, accuracy).

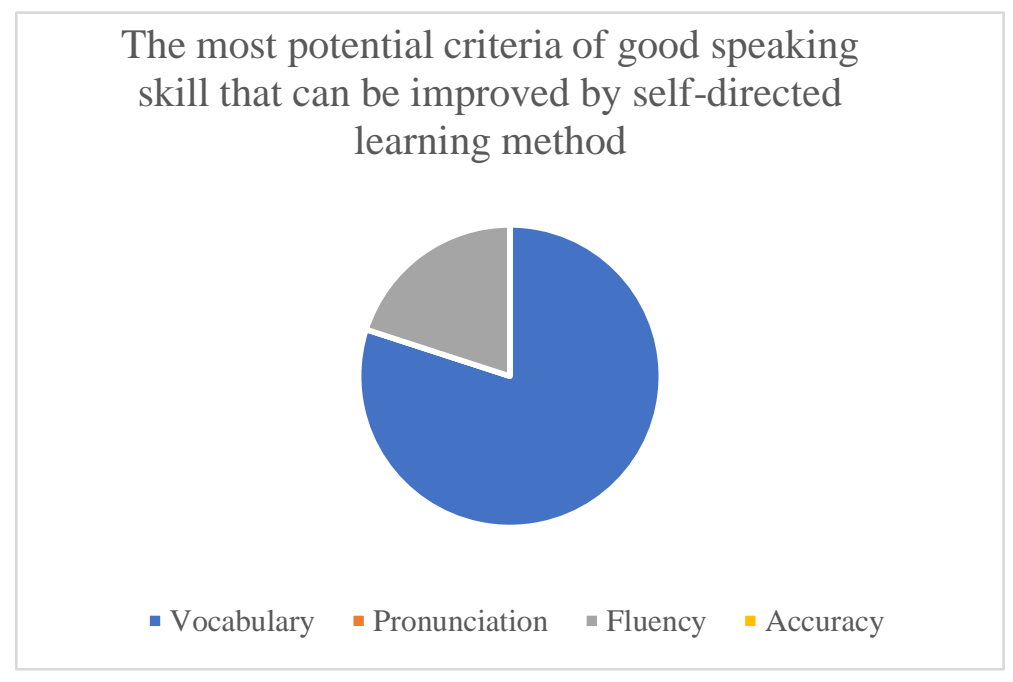

Figure 2: The percentage of most potential criteria in good speaking skill

The pie chart above is the result of the interview where participants in this study were presented with 4 criteria that need to be mastered in learning to speak English. $80 \%$ participants selected vocabulary as the most potential criterion. It means that four out of five participants agreed that vocabulary is one of the most potential to be improved with the SDL method on the use of media they usually use. In addition, the participants also had different learning activities when applying the SDL method. R1 usually watches reaction videos on YouTube because he gets a lot of 
vocabulary and expressions. He practiced the vocabulary either with his friends or independently. Besides YouTube, he also uses the PenPal application to communicate with someone abroad who is a native speaker. He analyzed the language normally used by native speakers to learn speaking skills. Furthermore, $\mathrm{R} 2$ revealed that the first reason he likes English is because of a game. Therefore, he made the game as a medium for SDL because he wanted to be able to translate menus and stories in a game. R3 built his vocabulary since he was young by comparing shows on TV which were dubbed in English and Indonesian. He can get a lot of vocabulary and understand the meaning well by comparing the sources. R4 usually learns by listening to songs on Spotify and googling about English material. From the Spotify application, he can understand the meaning of the song from the lyrics he reads, besides that he also uses the Google application by mentioning keywords so that the material he is looking for will appear. R4 did these activities independently when he was still in high school. He enjoys listening to Maroon Five songs and watching Hollywood movies with English subtitles. Of the two types of activities, he can improve his speaking ability by imitating the way native speakers speak in a song or film. he can also improve his listening skills because his ears are used to hearing English words so he can recognize English words from that. Therefore, students consider that vocabulary can make students' speaking skill are improved. It is because after getting a lot of vocabulary and expressions from the media, students can practice what they have learned.

\section{How students conduct self-directed learning process}

Independent learning activities carried out by students are very diverse. Each student has their own learning strategy with the media used is different from one another. For example, respondent number one (R1) usually has a conversation with a native speaker using the PenPal application on his smartphone. He also usually watches reaction videos on YouTube to broaden his knowledge of English such as English vocabulary and expressions. He claimed that he can be helped by the media in learning to pronounce some English words and also acquire many English expressions which are usually used by native speakers.

In addition, respondent number two (R2) applies the self-directed learning method to learn English through playing games, namely by translating the expressions that he encounters in the game. he acquires a lot of vocabulary in various contexts, namely through the translation of stories, menus, or in-game settings. In addition, apart from learning from games, he also usually learns from watching movies or YouTube videos. it does so by imitating the accent of a native speaker and learning new expressions from the dialogue in the video or film.

It is different with respondent number three (R3), he has a slightly different learning strategy from the other participants. He learned by comparing the TV show Spongebob Squarepants on cable TV which was dubbed in English with that on local TV which was dubbed in Indonesian. Therefore, he can understand that many expressions in the cartoon can be understood by the participants as a result of 
comparing two sources with different dubbing languages. In addition, he also plays console games such as the Playstation to learn English. He learned English by translating many words in the game that he didn't even know the meaning of. He is helped by his sister to translate the English words in the game or he finds the meaning of the game himself by checking the dictionary.

Respondent number four (R4) uses two kinds of devices, namely smartphones and laptops to carry out independent learning methods. He also usually uses search engines to find the material he needs by typing in keywords. In addition, he always trains with his friends or even alone if he wants to improve his speaking skills. He thinks that this method is more effective than learning through other media because if he has a speaking partner, there is a certain motivation that makes him able to improve his speaking ability. In addition, he also usually puts himself in front of the mirror to improve his speaking skills through self-study, he usually puts himself in front and does some monologues on some topics or he even practices with his friends while playing or hanging out. However, the first thing that motivated him to learn English was when he played the game and translated the English words in the game using a dictionary.

Respondent number five (R5) usually listens to some of his favorite songs, namely from Maroon Five to do independent learning. that activity he did when he was in high school. According to him, he can improve his English skills through independent learning strategies where the songs he listens to are his learning media. from the songs, he could recognize English phrases and words that he had never encountered before. Then he analyzes and understands these expressions so that the vocabulary he finds in the song can be applied to his speaking skills.

In addition, students have higher motivation and are also confident to learn English on their own outside the classroom by applying independent learning strategies (Hurriyah \& Humaira, 2017). This study also found that the enjoyment in learning English, especially speaking skills, can be felt by students by applying the right learning strategies. Those are, from the enjoyment of learning and enthusiasm emerges in students so they will have a major impact in learning to speak English.

\section{The media used by undergraduate students in conducting self-directed learning}

Students have very diverse learning media. Hurriyah and Humaira (2017) highlight that students usually learn English by watching YouTube videos, watching tv, listening to songs, watching movies, reading books, memorizing vocabulary and other activities in line with what the researchers found in this study. The pie chart below illustrates the media presentation used by undergraduate students in learning to speak English. 


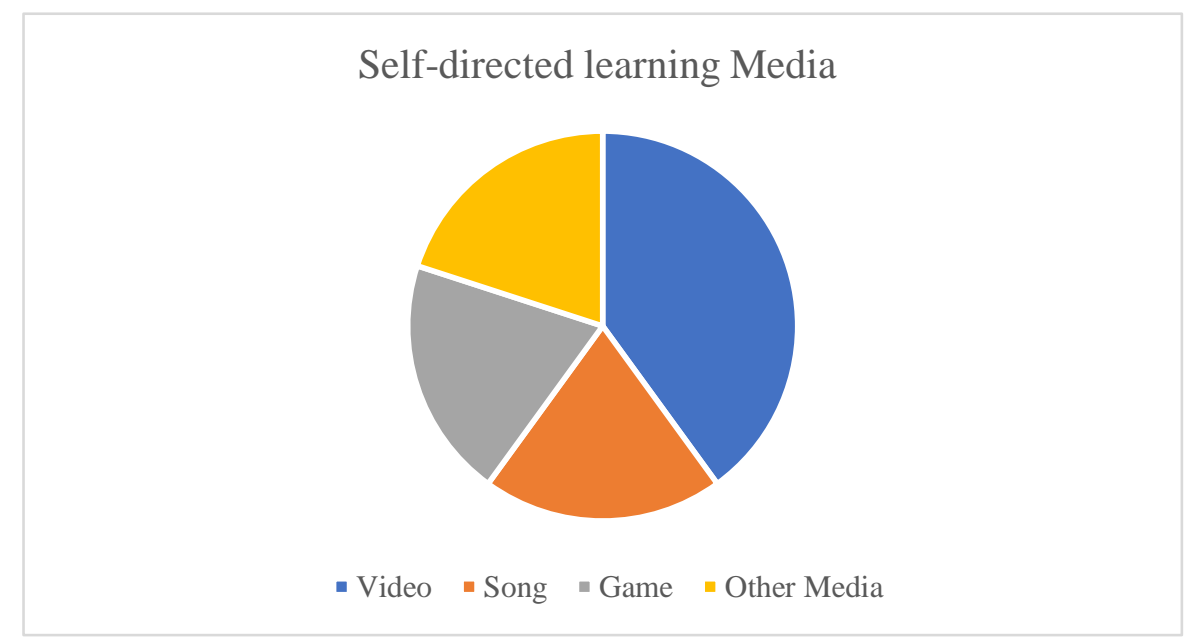

Figure 3: The percentage of self-directed learning media that students used

The researcher found that the media for learning to speak English used by students was very diverse and the number was not just one medium. However, in self-study, most of the participants were more inclined to audio-visual media. In implementing independent learning strategies, there are $40 \%$ of participants using video or audio-visual. This percentage shows that video is a suitable medium to improve students' English speaking skills because from what is shown from the video, students can understand the expressions and vocabulary well. In addition to videos, songs can also be used as a good medium to improve students' English skills. There are $20 \%$ of participants using songs as a medium to improve their English skills. From a song, students can understand the meaning conveyed by the author through the song. this is done by translating the lyrics of the song through a dictionary on the cellphone. In addition, games can also be used as an interesting medium for students to learn English in a fun way. According to research, there are $20 \%$ of participants learn English by playing games. Actually, some of the participants were initially interested in learning to speak English because of the game. there are other media that can help us to improve our English speaking skills such as applications on smartphones or computers, websites on the internet, TV shows, and many more. Previous research conducted by Hurriyah and Humaira (2017) stated that in determining the right learning strategy, students still had difficulties. However, the research found that students have high motivation and interest in learning if they have learning strategies that are in accordance with the activities they like. This is because the independent learning method can vary according to students' interests and watching videos is considered the most favorite activity to carry out independent learning to improve students' speaking skills.

\section{CONCLUSION}

This research aimed to describe the undergraduate students' perspective on selfdirected learning in speaking skill. Based on the result and discussions above, it can be concluded that all participants have been doing independent learning activities 
since they were teenagers even though they did not previously know about the selfdirected learning strategies themselves. They all enjoy learning English because they apply their favorite activities to study such as playing games, listening to songs, watching TV, watching online videos on Youtube, and watching movies. From the activities they like, they can organize their learning activities to achieve their learning goals. Their learning motivation can also grow if they learn through activities they like. According to students' views, the majority of students do learning activities by watching videos in some media such as TV, Youtube, or movies. Threfore, audio-visual media is a favorite tool that students choose in implementing self-directed learning.

\section{REFERENCES}

Arndt. (2017). Self-directed Learning for English Language Learners. ELF for English as a Lingua Franca Journal, V.3, vol 3, 2017, pp. 38-28.

Brown, H. Douglas. (2000). Principles of Language Learning and Teaching. London: Longman

Cameron, Deborah. (2001). Working with Spoken Discourse. Oxford: SAGE Publications, Ltd

C. Douglas and S. R. Morris, (2014) Student Perspectives on Self-Directed Learning. Journal of the Scholarship of Teaching and Learning, vol. 14, no. 1, February 2014, pp. 13-25

Creswell, J. (2003). Research design: Qualitative, quantitative and mixed methods approaches (2nded.). Thousand Oaks, CA: SAGE Publications.

Du, (2013) Student Perspective of Self-directed Learning. International Journal for the Scholarship of Teaching and Learning, vol. 7, no. 2, Article 24, 2013, pp. 1-16

Graham, S. (2007). Developing Speaking Skill in the Modern Foreign Language. In A Practical Guide to Teaching Modern Foreign Language in the Secondary School (p.58). Oxon: Routledge.

Hendry, G. D., Ginns, P. (2009). Readiness for self-directed learning: validation of a new scale with medical students. Med Teach, 31, 918-20.

Humaira, S. A. and Hurriyah, I. A. (2017). Students' Perspectives towards SelfDirected Learning out of Classroom. Andcances in Social Science, Education and Humanities Research, volume 145.

Johnson, K. and Morrow, K.E. (1981). Communication in The Classroom: Handbooks for Teachers' series. London: Longman.

Kim, H., Sefcik, J., S., and Bradway Christine. (2017). Characteristics of Qualitative Descriptive Studies: A Systematic Review. Res Nurs Health. 2017 February; 40(1): 23-42. doi:10.1002/nur.21768.

Koc , G. (2007). Yas, am boyu o“g renme [Lifelong learning]. In O”. Demirel (Ed.), Eg itimde yeni yo"nelimler [New trends in education] (pp. 209-222). Ankara: Pegem Akademi Yayıncılı

Long, H. B. (2007). Themes and theses in self-directed learning. International Journal of Self-Directed Learning, 4(2), 1-18. 
Koşar, G., \& Bedir, H. (2014). Strategies-Based Instruction: A Means of Improving Adult EFL Learners' Speaking Skills. International Journal of Language Academy, 2(3).

Moradi, H. (2017). The impact of M-learning on second language learning process among university students. Modern Journal of Language Teaching Methods, 7(8), 109-115.

O'Shea, E. (2003). Self-directed learning in nurse education: A review of the literature. Journal of Advanced Nursing 43, no. 1: 62_70.

Richards. (2001) Curriculum Development in Language Teaching. United Kingdom: Cambridge University Press

Sarwar, M., Alam, M., Hussain, A., Shah, A.A., \& Jabeen,M. (2014). Assessing English Speaking skills of Perspective teachers at entry and graduation level in teacher education program. Language Testing in Asia a Springer Open Journal.

Shahini, G., \& Riazi, A. M. (2011). A PBLT Approach to Teaching ESL Speaking, Writing, and Thinking Skills. Retrieved January 10, 2016, from http://eltj.oxfordjournals.org/content/65/2/170.full.pdf+html?sid=5d190b a9-9f26-4695b044-dab5ad0f4da4

Williamson. S. N (2007). Development of a self-rating scale of self-directed learning. Nurse Res. 14(2): 66-83.

Y. Vu and M. Shah. (2016) Vietnamese Students' SelfDirection In Learning English Listening Skill. Asian Englishes, vol 18, no. 1, 2016, pp. 53-66. 